\title{
Sequelae to preretinal haemorrhage in proliferative diabetic retinopathy
}

\author{
ENID TAYLOR \\ St Bartholomew's Hospital, London
}

Preretinal and vitreous haemorrhages are commonly seen in proliferative diabetic retinopathy. They occur particularly at the stage of active growth of the new vessels (Stage II: Dobree, I 964 ), and are less frequently seen when connective tissue is being laid down in and around groups of new vessels.

There is no doubt that repeated vitreous haemorrhages give rise to various forms of fibroplasia, which reduce the clarity of the media and in some cases lead to traction retinal detachment (Winter, 1967). Although there is general agreement about the occurrence of preretinal haemorrhages, there is no such agreement about the sequelae. Duke-Elder (1967) stated that small preretinal haemorrhages were rapidly absorbed with full restoration of vision, and that larger preretinal haemorrhages, which were absorbed more slowly, might damage the nerve-fibre layer with subsequent atrophy. Tolentino, Lee, and Schepens ( 1966 ), who studied haemorrhage and retinal detachment in 161 eyes, found that preretinal haemorrhages were either absorbed completely, leaving only a few white deposits of fibrin on the posterior detached vitreous face, or if very large, remained unabsorbed for months. Larsen (1960) described greyish silk-like veils lying in front of preretinal haemorrhages and found that they preceded detachment of the posterior vitreous face. He thought that they indicated degenerative changes in the hyaloid face. Wetzig and Jepson (1966) also mentioned a permanent reduction in vision after preretinal haemorrhage in one case, but did not discuss this further.

It is the purpose of the present paper to focus attention on the observed permanent sequelae to preretinal haemorrhage in a series of patients with proliferative diabetic retinopathy who have been reviewed regularly by serial fundus photography.

\section{Clinical material}

A series of 114 eyes from 59 patients have been studied over a period of 4 years, during which 44 preretinal haemorrhages were seen and photographed in 38 eyes. It is not suggested that this was the total number of such haemorrhages in these patients; as they are so localized, it is possible that some may have been unnoticed by the patient in the 3 to 4 -monthly intervals between out-patient attendances. The 44 preretinal haemorrhages were seen in all four quadrants of the fundus, often remote from the vessels which bled. The site of origin is often clearly indicated by a fine trail of clot.

\section{Observations}

On ophthalmoscopic examination at subsequent visits, no trace of these haemorrhages was seen in 37 cases, and no sequelae were seen in the serial fundus photographs.

Seven preretinal haemorrhages, however, gave rise to permanent sequelae. Three of these lay below the optic disc, two nasal to the optic disc, one in the lower temporal quadrant, and one at the posterior pole. 
It is from serial observations on these eyes that it has been possible to identify the stage leading to the permanent changes. The earliest change is visible ophthalmoscopicall $\overline{\underline{B}}$ after the haemorrhage has been present between 2 and 3 weeks. It consists of a grey shadow on the surface of the haemorrhage, which changes in a few days to fine, discretes irregular, greyish-white lines. Subsequently, over a period of weeks, these lines become more obvious and assume a lattice-like pattern. Examination with the fundus contact lens? at this stage shows that these are anterior to the surface of the haemorrhage and lie in the detached posterior vitreous face.

During the following 6 months, as the haemorrhage clears, the lines condense in the posterior vitreous face. These thickened areas finally assume one of two forms:

(I) The thickening may remain confined to that area of the posterior vitreous face whiclo lay over the preretinal haemorrhage. Its final form is a series of multiple irregular sma $\Phi$. bands, which obscure the underlying retina, but are separated from it by clear fluid in the preretinal space (Figure). This localized change was seen in four of the seven cases.

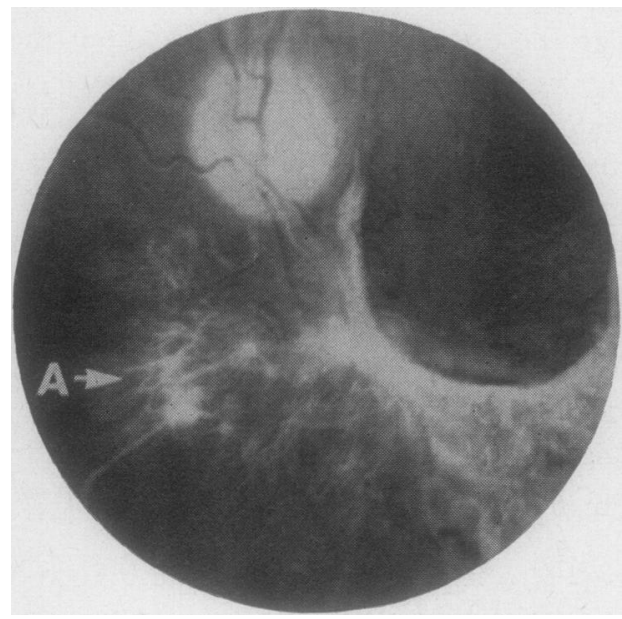

FIGURE Localized area of irregular band forme tion in the posterior vitreous face following sub-hyalo haemorrhage $(A)$

(2) In the remaining three cases, in addition to a localized area of thickening, a vitreous band developed, extending from the former area to the group of vessels which bled.

\section{Discussion}

It is seen from contact lens examination that these localized condensations of connective tissue and band formation lie in the detached posterior vitreous face, and one would expec్S them to have been formed from the hyaloid face.

The question remains why some preretinal haemorrhages behave in this manner, instea电 of clearing like the majority. It appears to be unrelated to the site of the haemorrhage and probably also to the size of the haemorrhage, as two of the seven haemorrhages were small and of the swallow's-nest type. The only common feature was that all the eye which developed thickening of the posterior vitreous face secondary to preretinal haemorit rhage had proliferative diabetic retinopathy with active connective tissue formation else where in the fundus. 


\section{Summary}

Preretinal haemorrhage in proliferative diabetic retinopathy has been observed in 44 cases, and the permanent sequelae in seven of these cases are described.

I wish to thank Mr. J. H. Dobree for his advice and encouragement, and for permission to publish details of cases under his care. The figure was kindly prepared by the Medical Illustration Department of St. Bartholomew's Hospital.

\section{References}

DOBREE, J. H. (1964) Brit. F. Ophthal., 48, 637

DUKE-ELDER, s. (1967) "System of Ophthalmology", vol. Io, p. I46. Kimpton, London LARSEN, H. W. (1960) Acta ophthal. (Kbh.), Suppl. 6o

TOlentino, F. I., LEe, P., and schepens, c. L. (1966) Arch. Ophthal. (Chicago), 75, 238

WETZig, P. c., and JEPSON, c. N. (I966) Amer. F. Ophthal., 62, 459

WINTER, F. c. (1967) Arch. Ophthal. (Chicago), 78, 229 